\title{
Traversal Struktur Data Bipartite Graph dalam Graph Database menggunakan Depth-First Search
}

\author{
Pradana Setialana $^{1}$, Muhammad Nurwidya Ardiansyah ${ }^{1}$ \\ ${ }^{1}$ Jurusan Pendidikan Teknik Elektronika dan Informatika, Universitas Negeri Yogyakarta \\ E-mail: pradana.setialana@uny.ac.id
}

\begin{abstract}
Bipartite graph combined with graph database produces the right solution in storing related data, but it requires modification of the traversal algorithm to trace data on the structure. One of the algorithms that can be used to traverse the graph structure is the depth-first search (DFS). This article aims to show a modification of the DFS algorithm that can be used to traverse a bipartite graph structure in a graph database. The modification of the algorithm is then carried out by traversal testing to determine the correctness of the algorithm, complexity analysis to determine the complexity of the algorithm in asymptotic notation, time velocity test, and memory usage to determine the efficiency of the algorithm when it is run. The results of the test show that the algorithm modification can carry out traversal properly. The algorithm complexity analysis shows that the complexity of the algorithm is $\mathrm{O}\left(n^{2}\right)$. The results of the speed and memory usage test show that the average speed in traversing is 9407.93 nanoseconds and the average memory usage is 30499929.07 bytes.
\end{abstract}

Keywords: data structure, bipartite graph, graph database, graph traversal, depth-first search

\begin{abstract}
ABSTRAK
Bipartite graph yang dikombinasikan dengan graph database menghasilkan solusi yang tepat dalam menyimpan data berelasi tetapi diperlukan modifikasi algoritme traversal agar dapat melakukan penelusuran data pada struktur tersebut. Salah satu algoritme yang dapat digunakan untuk melakukan traversal pada struktur graph adalah depth-first search (DFS). Artikel ini bertujuan untuk menunjukan modifikasi dari algoritme DFS yang dapat digunakn untuk melakukan traversal pada struktur bipartite graph dalam graph database. Modifikasi dari algoritme tersebut kemudian dilakukan uji traversal untuk mengetahui kebenaran algoritme, analisis kompleksitas untuk mengetahui kompleksitas algoritme dalam notasi asimtotik, uji kecepatan waktu dan pengguanaan memory untuk mengetahui efisiensi algoritme ketika dijalankan. Hasil dari pengujian menunjukan bahwa modifikasi algoritme tersebut dapat melakukan traversal dengan baik dan benar. Analisis kompleksitas algoritme menunjukan kompleksitas dari algoritm tersebut adalah $\mathrm{O}\left(n^{2}\right)$. Hasil uji kecepatan dan penggunaan memory menunjukan kecepatan rata-rata dalam melakukan traversal adalah sebesar 9407,93 nanosecond dan penggunaan memory ratarata sebesar 30499929,07 byte.
\end{abstract}

Kata kunci: struktur data, bipartite graph, graph database, graph traversal, depth-first search

\section{PENDAHULUAN}

Bipartite graph disebut juga bigraph yang mana dalam teori graph merupakan graph yang terdiri dari dua kelas node berbeda dimana node yang sama tidak dapat terhubung secara langsung [1] [2]. Karakteristik tersebut membuat bipartite graph tidak memiliki odd cycle [1]. Bipartite graph memiliki karakteristik yaitu terdiri dari dua jenis node yang berbeda. Bipartite graph dapat digunakan untuk membentuk struktur data yang berelasi seperti data hubungan keluarga atau data pohon keluarga karena memiliki karakteristik yaitu terdapat dua jenis node yang berbeda [3] [4]. Dalam data silsilah keluarga terdapat dua jenis data yaitu data keluarga dan data individu. Hal tersebut membuat bipartite graph cocok digunakan untuk data silsilah keluarga.

Untuk menyimpan struktur data bipartite graph dalam database dapat digunakan graph 
database. Graph database adalah database yang menggunakan konsep model data graph yaitu dimana node saling terhubung dengan node yang lain [5]. Graph database memiliki dua komponen yaitu vertices atau node dan relationship atau edges sehingga setiap data ataupun skemanya direpresentasikan dalam bentuk graph [6]. Graph database termasuk dalam jenis NoSQL sehingga memiliki schema yang fleksibel [6]. Bentuk graph ini memungkinkan graph database dapat memodelkan data yang berelasi dalam bentuk yang alami [6]-[8]. Salah satu graph database management system (DBMS) yang paling populer digunakan dalam skala besar adalah Neo4J [9]. Neo4J memiliki bahasa query untuk memanipulasi data dengan nama Cyper. Selain itu, proses manipulasi data dalam Neo4J juga dapat dilakukan melalui REST API dan Java API [7].

Kombinasi dari bipartite graph dalam graph database tersebut menghasilkan solusi tepat untuk menyimpan data berelasi dengan dua jenis node yang berbeda tetapi menimbulkan permasalahan baru yaitu bagaimana pencarian atau penelusuran (traversal) terhadap data yang ada dalam struktur tersebut.
Salah satu algoritme yang dapat digunakan untuk melalukan penelurusan (traversal) terhadap data dalam struktur graph adalah algoritme DFS. Algoritme DFS adalah algoritme yang bekerja dengan melakukan penelurusan dimulai dari tepi simpul secara mendalam artinya bahwa DFS menelusuri simpul pertama sampai level terdalam sempai tidak ditemukan lagi simpul yang terhubung [10]. Algoritme DFS dapat digunakan untuk melakukan penelurusan pada struktur graph tetapi perlu dilakukan modifikasi untuk melakukan penelurusan pada stuktur bipartite graph dalam graph database.

Berdasarkan permasalahan tersebut kami memodifikasi algoritme DFS untuk digunakan dalam penelusuran (traversal) data pada struktur data bipartite-graph dalam graph database. Hasil dari modifikasi algoritme DFS tersebut kemudian dilakukan uji traversal untuk mengetahui kebenaran dari algoritme, uji kompleksitas algoritme, uji efisiensi waktu dan uji efisiensi memory untuk untuk mengetahui performa dari algoritme tersebut.
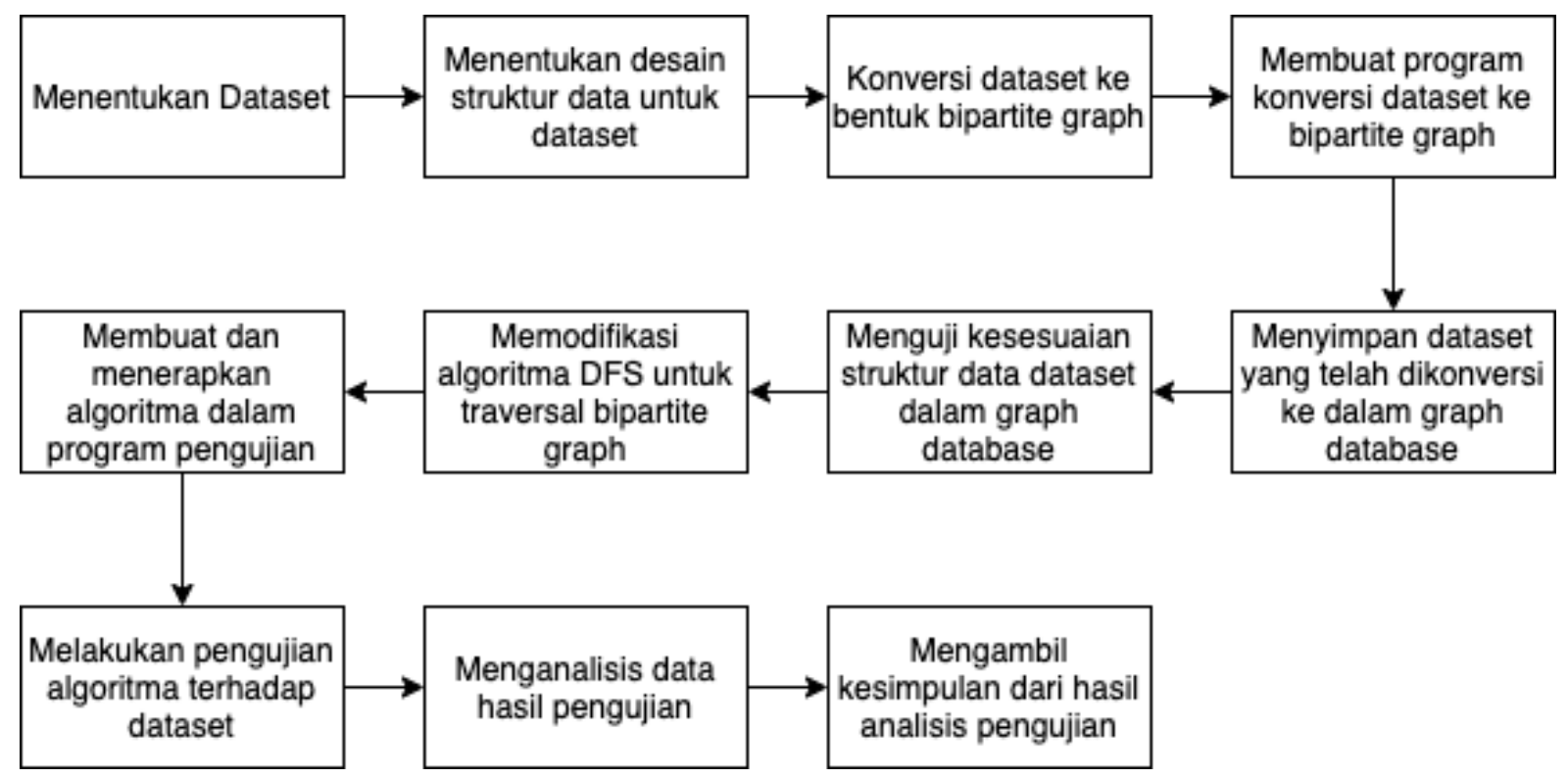

Gambar 1. Metode penelitian 


\section{METODE}

Penelitian ini dilakukan dengan beberapa tahapan untuk mendapatkan simpulan akhir. Pada Gambar 1 dapat dilihat terdapat beberapa tahapan dalam penelitian ini terdiri dari menentukan dataset, mengkonversi dataset ke bentuk struktur data bipartite graph, menyimpan dataset dalam bipartite graph, memodifikasi algoritme, melakukan pengujian algoritme, dan mengambil kesimpulan dari hasil pengujian. Tahapan menentukan dataset hingga konversi dataset telah dijelaskan pada penelitian sebelumnya [4] sehingga pada penelitian ini kami menjelaskan mengenai tahapan modifikasi algoritme DFS hingga mengambil kesimpulan.

Dataset yang digunakan dalam penelitian ini adalah data silsilah keluarga Presiden Amerika Serikat. Dataset tersebut berisi lebih dari 2000 individu yang saling terhubung dengan individu yang lain dalam ikatan keluarga. Data tersebut tersimpan dalam format GEDCOM yang merupakan format standar untuk menyimpan data silsilah keluarga [4].

Data tersebut kemudian dibentuk dan disesuaikan sesuai dengan struktur data bipartite graph. Struktur data bipartite graph untuk data hubungan keluarga dapat dilihat pada Gambar 3 . Gambar 3 menggambarkan data sililah keluarga dalam bentuk bipartite graph yaitu terdapat dua kelas node yaitu node individu dan node keluarga. Node individu digambarkan dalam bentuk bulat sedangkan node keluarga digambarkan dalam bentuk kotak. Dataset dalam struktur data bipartite graph kemudian disimpan dalam graph database Neo4j untuk kemudian dilakukan traversal dengan algoritme DFS yang telah dimodifikasi. Algoritme DFS adalah algoritme yang digunakan untuk penelusuran (traversal) dalam graph. Algoritme ini bekerja dengan cara melakukan penelusuran secara mendalam.

Untuk melakukan traversal dengan algoritme DFS pada struktur data bipartite graph dalam graph database perlu dilakukan modifikasi. Hasil dari modifikasi algoritme dalam notasi flowchart dapat dilihat pada Gambar 4. Sedangkan algoritme modifikasi DFS yang digunakan untuk melakukan traversal dalam bentuk source code dapat dilihat dalam pada Gambar 2.

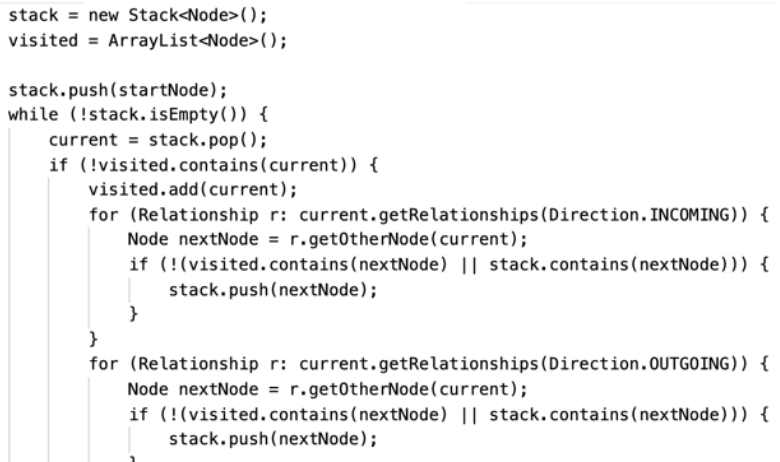

Gambar 2. Source code algoritme DFS untuk bipartite graph dalam graph database

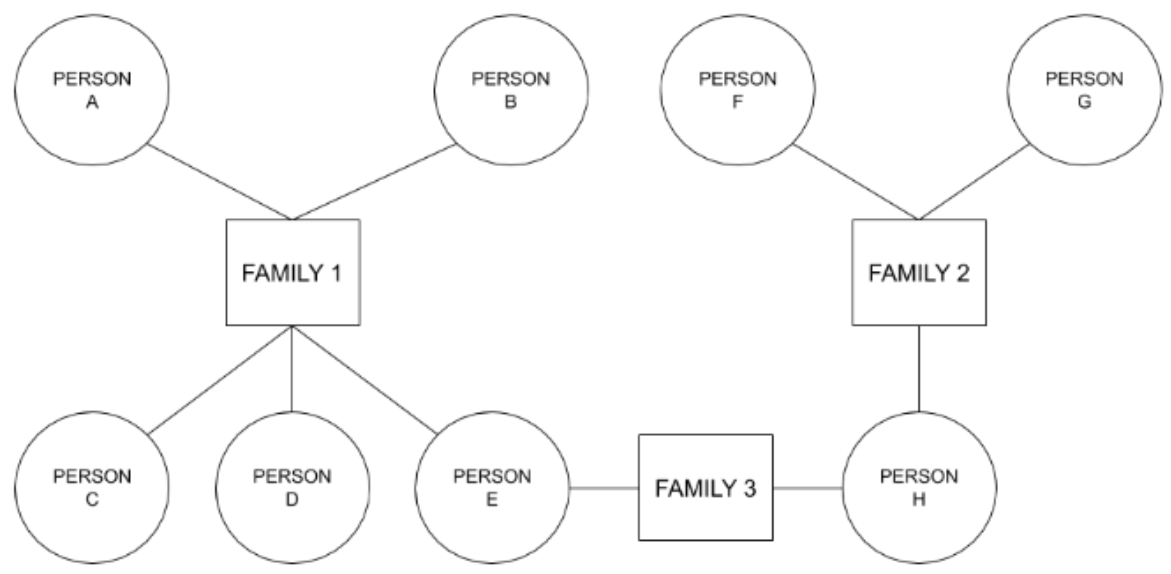

Gambar 3. Struktur Data Bipartite Graph 


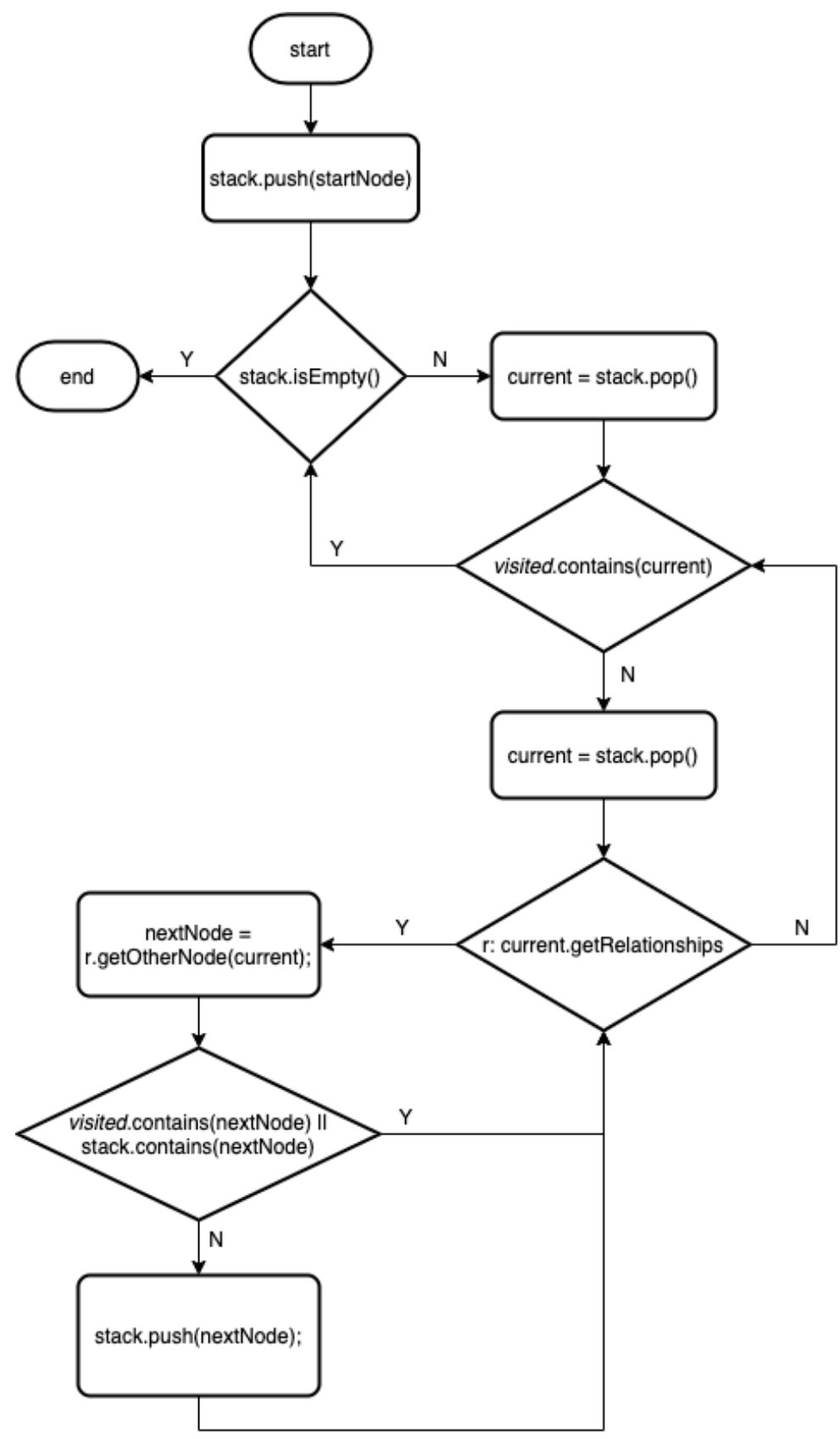

Gambar 4. Flowchart algoritme DFS untuk bipartite graph

Pengujian traversal dan analisis notasi asimtotik tidak bergantung pada alat yang digunakan untuk pengujian. Sedangkan Efisiensi waktu dan penggunaan memori sangat bergabung pada alat pengujian. Berikut adalah spesifikasi dari alat pengujian.

Bahasa Pemrograman : Java IDE

: Eclipse 4.12.0

Sistem Operasi

: Mac OS 11.2.3

Processor

: 2,3 GHz Core i5

RAM

\section{HASIL DAN PEMBAHASAN}

Untuk menguji kebenaran dari algoritme tersebut untuk dapat menelurusi bipartite graph maka dilakukan uji traversal, untuk mengetahui kompleksitas algoritme dilakukan analisis dalam notasi asimtotik. Sedangkan untuk mengetahui efisiensi dari algoritme maka dilakukan pengujian pada kecepatan waktu dan penggunaan memory algoritme DFS yang telah dimodifisikasi dalam melakukan penelurusan. 
Algoritme yang telah diimplementasikan dalam program kemudian diuji untuk melakukan traversal (penelurusan) terhadap data yang ada pada satu garis ikatan keluarga besar yaitu keluarga "George Washington /CASSIDY/". Hasil dari pengujian tersebut adalah dapat dilihat pada Gambar 5 .

Hasil tersebut menunjukan bahwa algoritme yang telah dibuat dan diterapkan dapat menelusuri keluarga "George Washington /CASSIDY/" dan menampilkan setiap node yang dilalui dalam penelurusan tersebut. Dalam Gambar 5 tersebut terlihat bahwa algoritme selain melalui node individu juga melalui node keluarga yang ditandai dengan simbol F. Untuk mengetahui seluruh node dilalui algoritme tersebut maka dilakukan perbandingan yang dapat dilihat pada Tabel 1. Berdasarkan hasil pengujian terlihat bahwa algoritme berhasil melakukan penelusuran terhadap semua node dalam data keluarga "George Washington /CASSIDY/" yaitu sebanyak total 101 node. Dari penelusuran tersebut juga diketahui bahwa keluarga "George Washington /CASSIDY/" memiliki 35 keluarga dengan 66 individu.

Tabel 1. Detail hasil pengujian traversal

\begin{tabular}{clc}
\hline No & Parameter & Keterangan \\
\hline 1 & Node pertama & $\begin{array}{c}\text { George Washington } \\
\text { /CASSIDY/ }\end{array}$ \\
2 & Node terakhir & Rachel \\
3 & $\begin{array}{l}\text { Jumlah node dalam } \\
\text { studi kasus }\end{array}$ & 101 \\
4 & $\begin{array}{l}\text { Jumlah node yang } \\
\text { dikunjungi }\end{array}$ & 101 \\
5 & Jumlah node individu & 66 \\
6 & Jumlah node keluarga & 35 \\
\hline
\end{tabular}

Selanjutnya kompleksitas algoritme Depth-first search (DFS) dihitung dengan menghitung jumlah langkah pada setiap baris pseudocode. Hasil dari perhitungan tersebut berbentuk notasi Big-O.

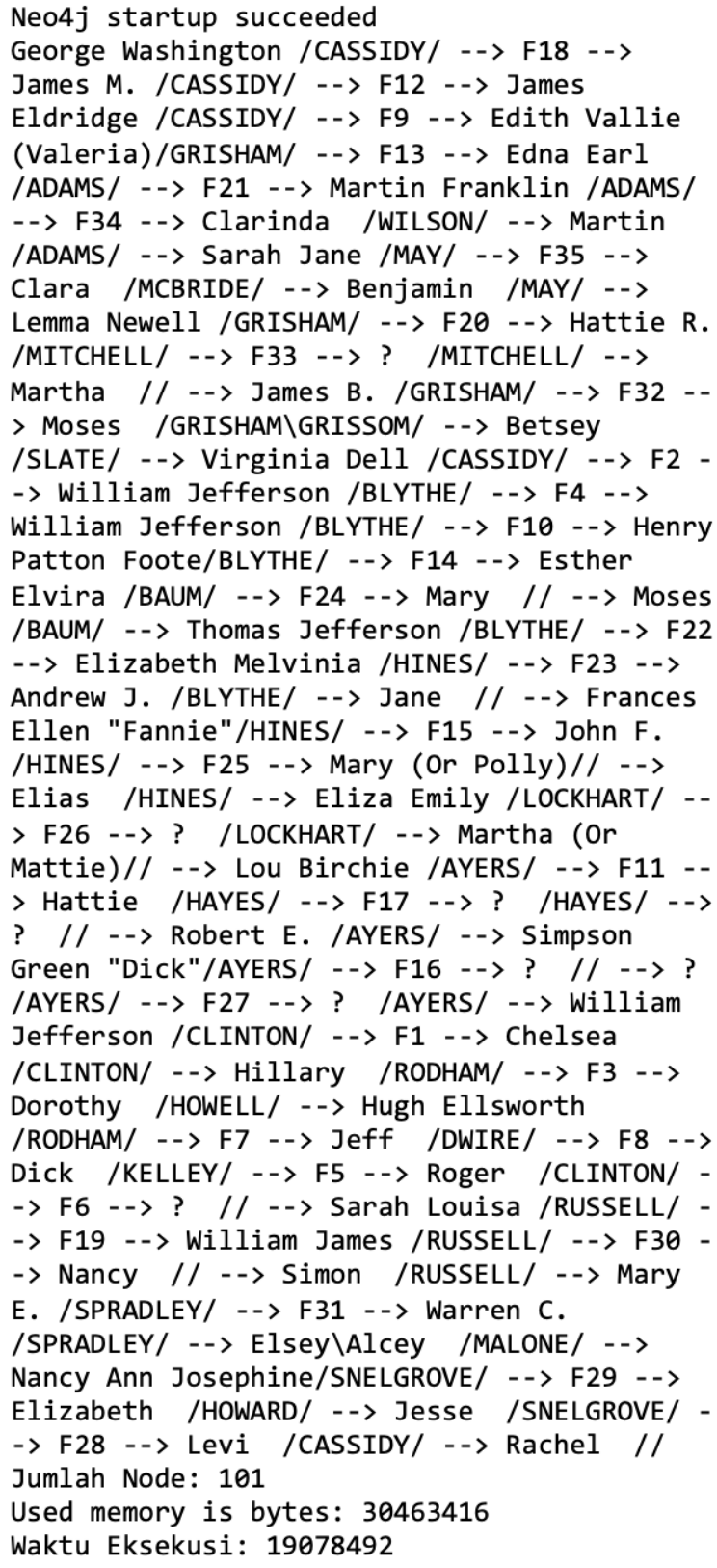

Gambar 5. Hasil traversal pada data keluarga "George Washington /CASSIDY/"

Perhitungan kompleksitas algoritme dilakukan terhadap pseudocode algoritme DFS untuk bipartite graph dalam graph database yang hasilnya dapat dilihat dalam Tabel 2 . Berdasarkan hasil tersebut dapat diketahui kompleksitas algoritme DFS untuk bipartite graph dalam graph database adalah $\mathrm{O}\left(n^{2}\right)$. 
Tabel 2. Kompleksitas Algoritme

\begin{tabular}{ccl}
\hline Baris & Frekuensi & \multicolumn{1}{c}{ Total } \\
\hline 5 & $\mathrm{n}$ & $\mathrm{n}$ \\
6 & 1 & $\mathrm{n}+1$ \\
$\ldots$ & $\ldots$ & $\ldots$ \\
9 & $\mathrm{n}$ & $(\mathrm{n}+1+\ldots) * \mathrm{n}$ \\
$\ldots$ & $\ldots$ & $\ldots$ \\
15 & $\mathrm{n}$ & $(\mathrm{n}+1+\ldots) *(\mathrm{n}+\ldots+\mathrm{n})$ \\
$\ldots$ & $\ldots$ & $\ldots$ \\
22 & 1 & $(\mathrm{n}+1+\ldots) *(2 \mathrm{n}+1+\ldots) \approx n^{2}$
\end{tabular}

Pengujian kedua kemudian dilakukan untuk mengetahui kecepatan algoritme tersebut dalam melakukan traversal pada keluarga "George Washington/CASSIDY/". Pada pengujian kedua ini dilakukan sebanyak 30 pengujian. Hasil pengujian dapat dilihat pada Error! Not a valid bookmark self-reference. dan Tabel 4 yang menunjukan kecepatan algoritme pada setiap percobaan dalam melakukan penelusuran pada keluarga "George Washington /CASSIDY/". Waktu yang diambil menggunakan satuan nanosecond yaitu $10^{-9}$ detik. Dari 30 percobaan tersebut dapat diambil ratarata kecepatan yang dapat dilihat pada Tabel 5 .

Tabel 3. Pengujian kecepatan algoritme tahap I

\begin{tabular}{cc}
\hline Percobaan & Waktu (ns) \\
\hline 1 & 8974 \\
2 & 8092 \\
3 & 6781 \\
4 & 7174 \\
5 & 8760 \\
6 & 7041 \\
7 & 9112 \\
8 & 8783 \\
9 & 8557 \\
10 & 6886 \\
11 & 9859 \\
12 & 6577 \\
13 & 8234 \\
14 & 7946 \\
15 & 7571 \\
\hline
\end{tabular}

Tabel 4. Pengujian kecepatan algoritme tahap II

\begin{tabular}{cc}
\hline Percobaan & Waktu (ns) \\
\hline 16 & 7029 \\
17 & 8652 \\
18 & 7421 \\
19 & 13658 \\
20 & 18332 \\
21 & 42831 \\
22 & 7858 \\
23 & 5301 \\
24 & 6424 \\
25 & 7374 \\
26 & 7302 \\
27 & 9824 \\
28 & 6851 \\
29 & 5150 \\
30 & 7884
\end{tabular}

Berdasarkan Tabel 5 dapat diketahui bahwa waktu rata-rata yang dibutuhkan algoritme tersebut untuk menelusuri data keluarga "George Washington /CASSIDY/" dalam struktur bipartite graph dalam graph database adalah 9407,93 nanosecond.

Tabel 5. Rata - rata kecepatan traversal

\begin{tabular}{lc}
\hline Keterangan & Waktu (ns) \\
\hline Waktu Maksimal & 42831 \\
Waktu Minimal & 5150 \\
Rata - Rata & 9407,93 \\
\hline
\end{tabular}

Pengujian efisiensi memori digunakan untuk mengetahui besar penggunaan memori yang digunakan ketika algoritme tersebut berjalan. Pengujian dilakukan ketika algoritme tersebut melakukan traversal pada keluarga "George Washington /CASSIDY/" sebanyak 30 kali. Hasil dari pengujian tersebut dapat dilihat pada Tabel 6. 
$\underline{\text { Tabel 6. Pengujian penggunaan memori }}$

\begin{tabular}{|c|c|}
\hline Percobaan & Penggunaan Memori (byte) \\
\hline 1 & 30531424 \\
\hline 2 & 30466800 \\
\hline 3 & 30466536 \\
\hline 4 & 30536216 \\
\hline 5 & 30464792 \\
\hline 6 & 30465952 \\
\hline 7 & 30535656 \\
\hline 8 & 30526184 \\
\hline 9 & 30531144 \\
\hline 10 & 30466528 \\
\hline 11 & 30536024 \\
\hline 12 & 30468432 \\
\hline 13 & 30527304 \\
\hline 14 & 30466320 \\
\hline 15 & 30534256 \\
\hline 16 & 30464920 \\
\hline 17 & 30469200 \\
\hline 18 & 30537480 \\
\hline 19 & 30463416 \\
\hline 20 & 30537688 \\
\hline 21 & 30534424 \\
\hline 22 & 30468056 \\
\hline 23 & 30533832 \\
\hline 24 & 30465840 \\
\hline 25 & 30535776 \\
\hline 26 & 30466192 \\
\hline 27 & 30531000 \\
\hline 28 & 30534872 \\
\hline 29 & 30465560 \\
\hline 30 & 30466048 \\
\hline
\end{tabular}

Hasil pengujian efisiensi memori pada tabel tersebut menunjukan besar memori yang dibutuhkan algoritme dalam melakukan traversal pada keluarga "George Washington /CASSIDY/" pada setiap percobaannya. Setelah dilakukan 30 kali percobaan, didapatkan ratarata pengguaan memori yang dapat dilihat pada Tabel 7.

Dari Tabel 7 dapat dilihat penggunaan memori minimal adalah sebesar 30463416 byte, penggunaan memori maksimal sebesar
30537688 byte dan rata-rata penggunaan memori adalah sebesar 30499929,07 byte.

Tabel 7. Rata-rata penggunaan memori

\begin{tabular}{lr}
\hline Keterangan & Memory (byte) \\
\hline Penggunaan memory minimal & 30463416 \\
Penggunaan memory maksimal & 30537688 \\
Rata-rata penggunaan memory & 30499929,07 \\
\hline
\end{tabular}

\section{SIMPULAN}

Algoritme DFS yang telah dimodifikasi dan telah diimplementasikan ke dalam program dapat menyelesaikan permasalahan penelusuran (traversal) data pada struktur data bipartite graph dalam graph database. Program dengan algoritme tersebut melakukan penelusuran (traversal) terhadap data yang ada pada satu garis ikatan keluarga besar yaitu keluarga "George Washington /CASSIDY/" dan menampilkan setiap node yang dilalui dalam penelurusan tersebut.

Hasil pengujian traversal dari algoritme tersebut diketahui bahwa jumlah node keseluruhan adalah 101, jumlah node yang dikunjungi adalah 101, jumlah node individu adalah 66 dan jumlah node keluarga adalah 35 . Hasil tersebut menunjukan bahwa kebenaran algoritme tersebut dalam melakukan traversal. Sedangkan hasil uji kompleksitas dari algoritme dapat diketahui bahwa kompleksitas pada algoritme DFS yang dimodifikasi adalah $\mathrm{O}\left(n^{2}\right)$.

Hasil uji efisiensi waktu dan efisiensi memory pada algoritme DFS yang telah dimodifikasi dilakukan sebanyak 30 kali percobaan. Dari 30 kali percobaan tersebut dapat diketahui bahwa waktu maksimal untuk melakukan penelurusan dalam graph adalah sebesar 42831 nanosecond, waktu minimal sebesar 5150 nanosecond dan rata-rata waktu yang diperlukan adalah sebesar 9407,93 nanosecond. Sedangkan pada penggunaan memory, memory yang diperlukan minimal 30463416 byte, penggunaan memory maksimal sebesar 30537688 byte dan rata-rata penggunaan memory adalah sebesar 30499929,07 byte. 


\section{DAFTAR PUSTAKA}

[1] R. Diestel, Graph Theory, vol. 3, no. 1. Springer, 2016.

[2] L. Lan, S. Ju, and H. Jin, "Anonymizing social network using bipartite graph," Proc. - 2010 Int. Conf. Comput. Inf. Sci. ICCIS 2010, pp. 993-996, 2010, doi: 10.1109/ICCIS.2010.245.

[3] A. Bezerianos, P. Dragicevic, J. D. Fekete, J. Bae, and B. Watson, "GeneaQuilts: A system for exploring large genealogies," IEEE Trans. Vis. Comput. Graph., vol. 16, no. 6, pp. 10731081, 2010, doi: 10.1109/TVCG.2010.159.

[4] P. Setialana, T. B. Adji, and I. Ardiyanto, "Analisis Bipartite Graph, Ore-Graph dan P-Graph untuk Struktur Data Genealogy dalam Graph Database," in The 9th National Conference on Information Technology and Electrical Engineering, 2017, pp. 173-180.
[5] Z. J. Zhang, "Graph Databases for Knowledge Management," IT Prof., vol. 19, no. 6, pp. 26-32, 2017, doi: 10.1109/MITP.2017.4241463.

[6] R. Angles and C. Gutierrez, "Survey of graph database models," ACM Comput. Surv., vol. 40, no. 1, pp. 1-39, 2008, doi: 10.1145/1322432.1322433.

[7] I. Robinson, J. Webber, and E. Eifrem, Graph Databases. Sebastopol: O'Reilly Media, Inc, 2015.

[8] D. Shimpi, "An overview of Graph Databases," IJCA Proc. Int. Conf. Recent Trends Inf. Technol. Comput. Sci. 2012, vol. ICRTITCS, no. 3, pp. 16-22, 2013.

[9] R. Kumar Kaliyar, "Graph databases: A survey," Int. Conf. Comput. Commun. Autom. ICCCA 2015, pp. 785-790, 2015, doi: 10.1109/CCAA.2015.7148480.

[10] T. H. Cormen, C. E. Leiserson, R. L. Rivest, and C. Stein, Introduction to Algorithms. MIT Press, 2009. 